\title{
Düşük Dayanımlı Betonların CFRP Kompozitler ile Güçlendirilmesi ve Sonlu Eleman Yöntemi ile Analizi
}

\author{
${ }^{1}$ Ameen Alfaqeeh , ${ }^{* 2}$ Ali Sarıbıyı ve ${ }^{3}$ Ergün Nart \\ ${ }^{1}$ Sakarya Üniversitesi, Mühendislik Fakültesi, İnşaat Mühendisliği Bölümü, Türkiye \\ ${ }^{* 2}$ Sakarya Uygulamalı Bilimler Üniversitesi, Teknoloji Fakültesi, İnşaat Mühendisliği Bölümü, Türkiye \\ ${ }^{3}$ Sakarya Uygulamalı Bilimler Üniversitesi, Teknoloji Fakültesi, Mekatronik Mühendisliği Bölümü, Türkiye
}

\section{ÖZET}

Bu çalışmada, düşük dayanımlı betonlar, eksenel basınca karşı Karbon Elyaf Takviyeli Polimer (CFRP) kompozitler ile güçlendirilmiş ve güçlendirilen betonların davranışları üzerine bir sonlu elemanlar programı (Abaqus) ile modelleme çalışması yapılmıştır. Betonlar iki farklı basınç dayanımında, standart silindir boyutlarında ve 12 MPa'nın basınç dayanımının altında üretilmiş̧ir. Betonlar tek doğrultulu CFRP ile dışarıdan enine sarılarak güçlendirmiş ve test edilmiştir. CFRP ile güçlendirilen betonların davranışı oluşturulmuş ve sonlu elemanlar programı ile modellenmiştir. Sonlu Elemanlar Metodu (SEM) programında istenen parametreler, deneysel çalışmalardan, literatürden, modellemede yaygın olarak kullanılan bazı temel formüllerden ve ürün kataloğundan elde edilmiştir. Gerekli parametreler SEM paket programına girilerek düşük dayanımlı beton modeli oluşturulmuştur. Ağ boyutu ve geometrik şekli, genişleme açısı gibi model parametreleri beton davranışını önemli ölçüde etkilediği için düşük dayanımlı betonlara uygun parametreler tespit edilmiştir. Beton modeli deneysel çalışmalar ile doğrulandıktan sonra CFRP ile güçlendirilmiş betonlar modellenmiştir. SEM'de CFRP kompozitler kabuk eleman olarak tanımlanmış ve beton yüzeyine bağlanmışıtır. Elde edilen sonuçlara göre; CFRP kompozitler ile güçlendirilen düşük dayanımlı betonların dayanımı ve şekil değiştirme kapasitesi önemli ölçüde artmıştır. CFRP ile güçlendirilen betonların davranışı model programı ile doğrulanmıştır.

Anahtar Kelimeler: CFRP, güçlendirme, sonlu elemanlar metodu, SEM, düşük dayanımlı beton.

\section{Strengthening Low-Strength Concrete with CFRP Composites and Analysis by Finite Element Method}

\begin{abstract}
In this study, Low-strength concretes were strengthened with Carbon Fiber Reinforced Polymer (CFRP) composites under axial compressive loads and modeled with a finite element program (Abaqus). Concretes were produced at two different compressive strength, standard cylinder dimensions and lower than pressure strength of $12 \mathrm{MPa}$ Concretes were reinforced with unidirectional CFRP wrapped cross outside and tested. The concrete behavior reinforced by CFRP is established and modeled with the finite element program. The parameters in the Finite Element Method (FEM) program are obtained from experimental studies, literature, some basic formulas widely used in modeling, and the product catalog. The required parameters are entered into the FEM program to verify the low-strength concrete model. Proper parameters are determined for low strength concrete, because mesh size and geometric shape, dilation angle, etc., are changed significantly the behavior of concrete Once the concrete model has been confirmed by experimental studies, the modeling of concrete reinforced with CFRP has begun. In FEM program, CFRP composites are defined as shell elements and connected to the concrete surface. According to the results the strength and strain capacity of low-strength concretes strengthened with CFRP composites has increased significantly. The behavior of concrete reinforced with CFRP was verified by the model program.
\end{abstract}

Keywords: CFRP, strengthening,finite element model, FEM, low strength concrete.

\section{Giriş}

Türkiye'de meydana gelen depremler, mevcut betonarme yapıların önemli bir bölümünün birçok açıdan güçlendirilmesi gerektiğini ortaya koymaktadır. Depreme karşı dayanımı düşük olan betonarme yapıların sayısının fazla olması, bu yapıların halen faal olması gibi nedenler birçok

*Corresponding author: Adres:. Sakarya Uygulamalı Bilimler Üniversitesi, Teknoloji Fakültesi, İnşaat Mühendisliği Bölümü 54187 Sakarya TÜRKIYE E-mail adres: alisaribiyik@sakarya.edu.tr 
problemi de beraberinde getirmektedir. Toplu yerleşim yerlerinde kentsel dönüşüm ile yapılar yıkılarak yerine yeni depreme dayanıklı ve birçok açıdan daha etkili olanları inşa edilmektedir. Ancak burada yüksek maliyetler ve şehrin dokusundan farklı mimariler ortaya çıkmaktadır. Betonarme yapılar farklı şekillerde onarılarak ve güçlendirilerek depremlere dayanıklı hale getirilmektedir. Depreme karşı betonarme yapıların en önemli elemanı kolonlar ve perdelerdir. Türkiye'deki meydana gelen depremler sonrasında betonarme binaların çoğunda betonların basınç dayanımlarının oldukça düşük olması, kolon etriyelerinin yeterli sıklık ve miktarda olmaması, etriye kancalarının uygunsuzluğu, kolon sürekliliğinin sağlanamaması vb. nedenler ile betonarme yapılar hasar görmekte veya yıkılmaktadır [1]-[11].

Betonarme kolonların onarım ve güçlendirilmesinde çeşitli yöntemler kullanılmaktadır. Kolonların betonarme ile mantolanması kullanılan yöntemlerin başında gelmektedir. Ancak bu yöntemler ile yapılan güçlendirmelerde oluşan boyut artışı alan kayıplarına sebep olmakta, güçlendirilme yapılırken yapının kullanımı mümkün olmamaktadır. Yapı ağırlığııı artırmayan, kolay ve hızlı uygulanabilen, elemanların taşıma kapasitelerini önemli ölçüde artıran, güçlendirme sırasında yapının kullanımına olanak sağlayan Elyaf Takviyeli Polimer (FRP) kompozitler bu tür problemleri azaltan önemli bir onarım ve güçlendirme malzemesidir. Betonarme kolonlar FRP kompozitler ile sarılarak etkili bir şekilde güçlendirilebilmektedir [12][27]

Beton ve FRP kompozitler ile güçlendirilmiş betonlar üzerine yapılan deneysel çalışmalar ile kolonların davranışı araştırılmaktadır. Ayrıca yapılan sonlu elemanlar model çalışması, SEM paket programı ile deney parametreleri artırılarak yeni ve etkili güçlendirme yöntemleri üzerinde çalışılmaktadır. Beton dayanımının ve içeriğinin değişmesi, beton davranışını etkilemektedir. Ayrıca beton davranışının başlangıçtan itibaren doğrusal olmaması ve karmaşıklığı sonlu elemanlar ile modellenmesini zorlaştırmaktadır. Farklı dayanımdaki betonların sonlu elemanlar paket programları modellenmesi ve FRP kompozitler ile güçlendirilmesi üzerine birçok çalışma yapılmıştır[28]-[32].

$\mathrm{Bu}$ çalışmada, mevcut betonarme yapılardaki betonlar dikkate alınarak, standart silindirik boyuttaki betonlar eksenel basınca karşı Karbon Elyaf Takviyeli polimer (CFRP) kompozitler ile güçlendirilmiştir. Güçlendirilen betonların davranışları bir sonlu elemanlar paket programı ile modellenmiştir. Elde edilen deneysel ve model sonuçları karşılaştırmalı olarak analiz edilmiştir.

\section{Malzeme ve metot}

\subsection{Malzemeler}

Betonların üretiminde CEM IV/B 32, R çimento, şebeke suyu, 0-4 mm doğal kum ve 4-16 mm elek çapında mıcır kullanılmıştır. Betonlar TS 802 yardımı ile iki farklı basınç dayanımında üretilmiştir. $1 \mathrm{~m}^{3}$ beton içerisindeki malzemelerin miktarları Tablo 1'de gösterilmektedir. Betonların güçlendirilmesinde tek doğrultulu karbon elyaf kumaş kullanılmıştır. Karbon elyaf kumaşın dokuma kalınlığı: 0,166 mm, çekme dayanımı: $3900 \mathrm{MPa}$, çekme elastisite modülü: $230 \mathrm{GPa}$, kopma uzaması: \%1,5; karbon elyaf kumaşın beton yüzeylerine yapıştırılmasında kullanılan epoksi reçinenin çekme dayanımı: $30 \mathrm{MPa}$, çekme elastisite modülü: 4,5 GPa, kopma uzaması: \%0,9 olarak ürün kataloğundan alınmıştır. 
Tablo $1.1 \mathrm{~m}^{3}$ beton içerisindeki malzemelerin miktarları

\begin{tabular}{lll}
\hline Malzemeler & S1 Betonu & S2 Betonu \\
\hline Çimento $(\mathrm{kg})$ & 257 & 269 \\
Kum $(\mathrm{kg})$ & 783 & 784 \\
1 Nolu micır $(\mathrm{kg})$ & 1174 & 1176 \\
Su $(\mathrm{kg})$ & 180 & 175 \\
Toplam $(\mathrm{kg})$ & 2394 & 2404 \\
Çökme miktarı $(\mathrm{cm})$ & 15 & 12 \\
Su/çimento oranları $(-)$ & 0.7 & 0.65 \\
\hline \hline
\end{tabular}

\subsection{Deneysel Çalışmalar}

\subsubsection{Test numuneleri ve araştırma parametreleri}

Deneysel çalışmada kullanılmak üzere 20 adet beton, iki farklı basınç dayanımında (S1 ve S2) standart silindir boyutlarda (150 mm çap ve $300 \mathrm{~mm}$ yüksekliğinde) üretilmiştir. Betonlarından dörder adedi kontrol betonu, diğerleri güçlendirme için ayrılmıştır. Bir kat karbon elyaf kumaş sarılarak güçlendirilen S1 betonları, S1-CFRP1; bir kat karbon elyaf kumaş sarılarak güçlendirilmiş S2 betonları, S2-CFRP1 ile simgelenmiştir. Eksenel doğrultuda ve sabit hızlı yükleme altında test edilmiş numunelerin ortalama test sonuçları Tablo 2'deki sunulmuştur. Numune gruplarının eksenel basınç gerilme ve birim şekil değiştirme grafikleri hesaplanarak çizilmiştir. Basınç gerilme ve birim şekil değiştirme grafikleri bulunmuştur. Güçlendirilen betonların davranışları bir sonlu elemanlar programı ile modellenmiştir.

Tablo 2. Betonların gerilme-şekil değiştirme artış oranları

\begin{tabular}{lll}
\hline Numune ismi & Basınç dayanımı(MPa) & Şekil değiştirme \\
\hline \hline S1 & 6,75 & 0,0036 \\
S1-CFRP1 & 31,06 & 0,0262 \\
S2 & 11,02 & 0,0029 \\
S2-CFRP1 & 35,60 & 0,0208 \\
\hline
\end{tabular}

\subsection{Sonlu Elemanlar Model çalışmaları}

Sonlu elemanlar yöntemi basitçe diferansiyel denklemleri, denklem sistemlerine çevirerek çözen bir sayısal yöntemdir. Bu yöntem, kabul edilebilir bir yaklaşımla sayısal çözüm üretilmektedir. Son yıllarda bilgisayar programları, abaqus CEA programı gibi, daha hızlı ve çabuk sayısal sonuç üretmek için, sonlu elemanlar metodunu (SEM) hesap yöntemlerinde etkili bir şekilde kullanmaktadırlar. Bu çalışmada silindir boyutlardaki beton ve CFRP ile güçlendirilmiş beton SEM ile modellenmiştir. Programda yükleme, deneyde olduğu gibi beton üst yüzeyine yapısal yayılı (structural distributing) olarak yapılmıştır. Sınır şartları, alt yüzeyi ankastre ve üst yüzeyi ise serbest olarak düzenlenmiştir. Bu arada CFRP kompozit beton yan yüzeylerine kabuk (Shell) olarak tanımlanmıştır. Beton üzerine yapılan SEM analizlerinde, mesh yakınsama işlemi ile uygun bir eleman boyutu belirlenmiş ve 20 düğüm noktalı Solid eleman türü seçilmiştir. Ayrıca 
analiz türü olarak "statik-riks" analizi olarak tanımlanmıştır (Şekil 1). Malzeme modeli olarak beton hasar plastisite modeli seçilmiştir.

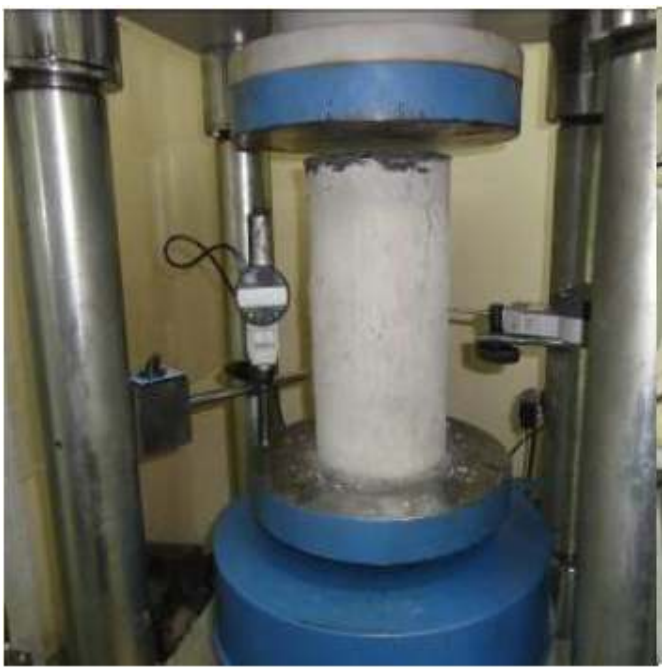

a) Basınç deneyi düzeneği

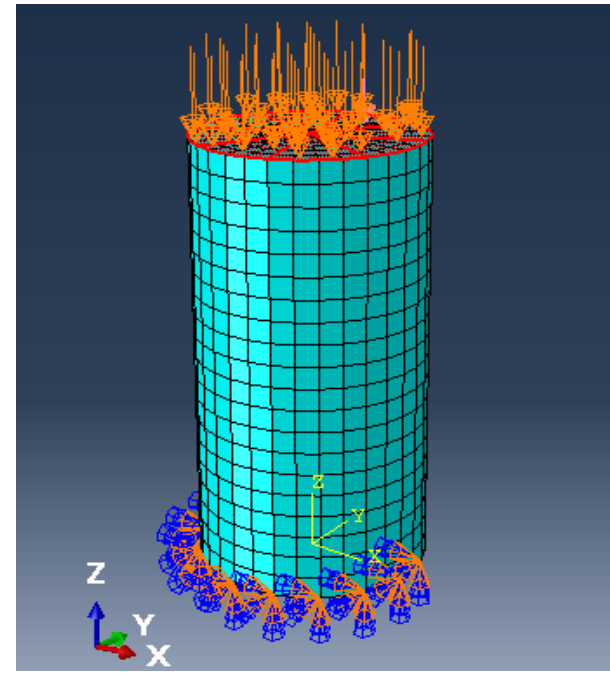

b) Beton modeli

Şekil 1. Deney düzeneği (a) ve SEM beton modeli (b)

\subsubsection{Beton Hasar Plastisite}

Beton Hasar Plastisite (BHP) yöntemi, beton için sürekli plastisiteye dayalı bir hasar modelidir. BHP yönteme göre çekme çatlaması ve basınç kırılması olmak üzere betonda temel iki önemli yenilme mekanizması vardır. Hasarın oluşumu ve elastik rijitlikte değişimi tanımlamak için iki birim şekil değiştirme değişkeni $\left(\varepsilon_{\mathrm{t}}^{\sim \mathrm{pl}}\right.$ ve $\left.\varepsilon_{\mathrm{c}}^{\sim \mathrm{pl}}\right)$ sırasıyla çekme ve basma eşdeğer plastik gerilmeler olarak adlandırılır. Betonun mekanik davranışları hakkındaki ana varsayımlar tartışılmaktadır [33], [34] ,[35]. ABAQUS/Standart User Manual'den alınan BHP, betonun tek eksenli çekme ve basınç gerilmeleri altında gerilme-şekil değiştirme davranışı Şekil 2a,-2b'deki gibi ifade edilmektedir[36].

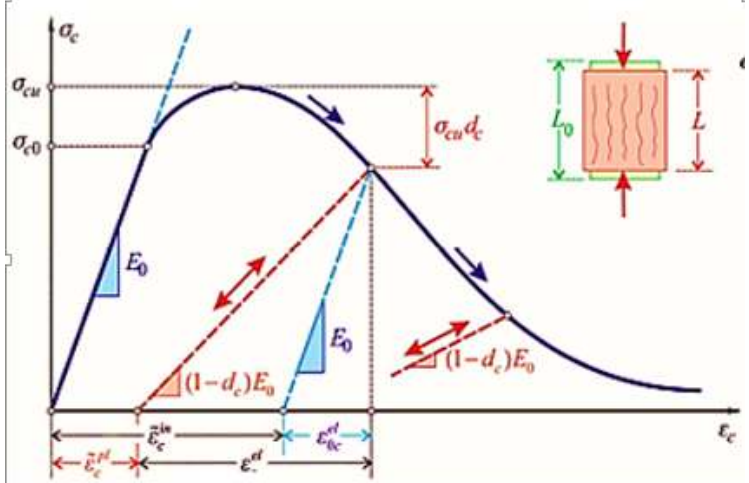

a) Eksenel basınç altında beton davranışı

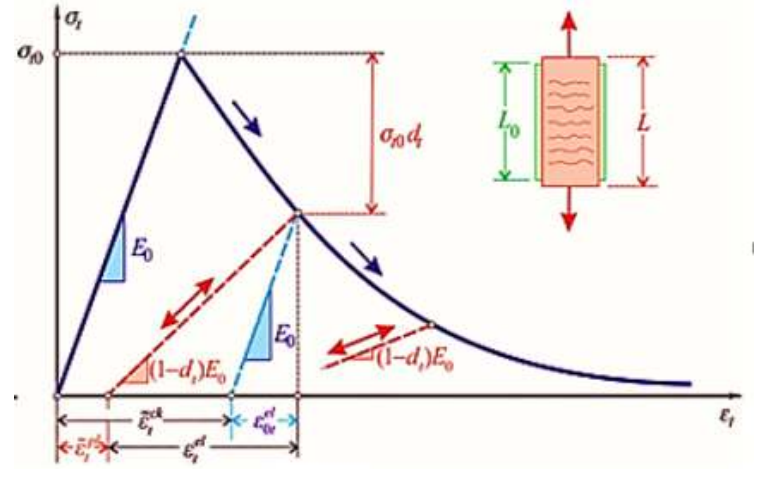

b) Eksenel çekme altında beton davranışı Şekil 2. Eksenel çekme (a) ve basınç (b) altında beton davranışı 
Tek Eksenel basınç kuvveti altında ise gerilmeler $6_{\mathrm{c} 0}$ değerine kadar doğrusal elastik kabul edilir. Beton davranışı çekme gerilmesine $\left(6_{\mathrm{t} 0}\right)$ kadar doğrusal bir ilişki izler. Maksimum çekme gerilmesine ulaşılmasıyla betonda çekme çatlağı oluşur. Elastik rijitliğin bozulması, sıcaklığın ve alan değişkenlerinin işlevleri olduğu varsayılan iki hasar değişkeniyle $\left(d_{t} v e d_{c}\right)$ karakterize edilmektedir:

$$
\begin{aligned}
& \mathrm{d}_{\mathrm{t}}=\mathrm{d}_{\mathrm{t}}\left(\varepsilon_{\mathrm{t}}^{\sim \mathrm{pl}}, \theta, \mathrm{f}_{\mathrm{i}}\right) ; 0 \leq \mathrm{d}_{\mathrm{t}} \leq 1, \\
& \mathrm{~d}_{\mathrm{c}}=\mathrm{d}_{\mathrm{c}}\left(\varepsilon_{\mathrm{c}}^{\text {pl }}, \theta, \mathrm{f}_{\mathrm{i}}\right) ; 0 \leq \mathrm{d}_{\mathrm{c}} \leq 1 .
\end{aligned}
$$

Grafiklerde $\mathrm{E}_{0}$ malzeme hasarsız elastisite modülünü göstermekte ve ${\tilde{\varepsilon_{\mathrm{c}}}}^{\sim \mathrm{pl}},{\tilde{\varepsilon_{\mathrm{t}}}}^{\sim \mathrm{pl}}, \varepsilon_{\mathrm{c}}^{\sim \text { in }}, \varepsilon_{\mathrm{t}}^{\sim \text { in }}$ sırasıyla; eksenel basınç plastik şekil değiştirmesini, eksenel çekme plastik şekil değiştirmesini ve elastik olmayan basınç ve çekme şekil değiştirmelerini göstermektedir. Gerilme $\left(\sigma_{t}, \sigma_{c}\right)$-şekil değiştirmeler $\left(\varepsilon_{t}, \varepsilon_{c}\right)$ arasındaki bağıntı aşağıdaki formüller ile ifade edilmektedir:

$$
\begin{aligned}
& \sigma_{\mathrm{t}}=\left(1-\mathrm{d}_{\mathrm{t}}\right) \mathrm{E}_{0}\left(\varepsilon_{\mathrm{t}}-\varepsilon_{\mathrm{t}}^{\sim \mathrm{pl}}\right), \\
& \sigma_{\mathrm{c}}=\left(1-\mathrm{d}_{\mathrm{c}}\right) \mathrm{E}_{0}\left(\varepsilon_{\mathrm{c}}-\underset{\varepsilon_{\mathrm{c}}^{\sim p l}}{\sim{ }^{2}}\right),
\end{aligned}
$$

"Etkin" olan çekme ve basınç kohezyonu (cohesion) gerilmelerini $\left(\sigma_{\mathrm{t}}^{-}, \sigma_{\mathrm{c}}^{-}\right)$şu şekilde tanımlanmektedir:

$$
\begin{aligned}
& \sigma_{\mathrm{t}}^{-}=\frac{\sigma_{\mathrm{t}}}{\left(1-\mathrm{d}_{\mathrm{t}}\right)}=\mathrm{E}_{0}\left(\varepsilon_{\mathrm{t}}-\varepsilon_{\mathrm{t}}^{\sim \mathrm{pl}}\right), \\
& \sigma_{\mathrm{c}}^{-}=\frac{\sigma_{\mathrm{c}}}{\left(1-\mathrm{d}_{\mathrm{c}}\right)}=\mathrm{E}_{0}\left(\varepsilon_{\mathrm{c}}-\varepsilon_{\mathrm{c}}^{\sim \mathrm{pl}}\right),
\end{aligned}
$$

Çekme rijitliği ve tek eksenel basınç altında doğrusal olmayan birim şekil değiştirmeler $\operatorname{plastik}\left(\varepsilon_{\mathrm{c}}^{\sim \mathrm{pl}}, \varepsilon_{\mathrm{t}}^{\sim \mathrm{pl}}\right)$ birim şekil değiştirmelere aşağıdaki formülle tanımlanır.

$\varepsilon_{\mathrm{c}}^{\sim \mathrm{pl}}=\varepsilon_{\mathrm{c}}^{\sim \text { in }}-\frac{\mathrm{d}_{\mathrm{c}}}{\left(1-\mathrm{d}_{\mathrm{c}}\right)} \frac{\sigma_{\mathrm{c}}}{\mathrm{E}_{0}}$,

$\varepsilon_{\mathrm{t}}^{\sim \mathrm{pl}}=\varepsilon_{\mathrm{t}}^{\sim \mathrm{ck}}-\frac{\mathrm{d}_{\mathrm{t}}}{\left(1-\mathrm{d}_{\mathrm{t}}\right)} \frac{\sigma_{\mathrm{t}}}{\mathrm{E}_{0}}$,

Modelde kullanılan beton mekanik özellikleri deney sonuçlarından elde edilerek SEM'e girilmiştir[37]. BHP modeli yukarıda belirtilen denklemler referans alınarak oluşturulmuştur. BHP yönteminde Dilasyon Açısı, betonda plastik hacimsel değişmeleri kontrol eden parametredir ve nümerik SEM analizlerde DA yakın değerler için uygunluk araştırmasıyla belirlenmiştir. Eksantriktik parametresi (e) değer olarak 0,1 kabul edilmektedir. $\left(\sigma_{\mathrm{bo}} / \sigma_{\mathrm{co}}\right)$ değerinde analizlerde varsayılan değer olarak 1,16 kabul edilmektedir. $\mathrm{K}_{\mathrm{c}}$ değeri nümerik SEM analizlerde beton için tipik değer olarak verilen 0,667 kabul edilmiştir. $11 \mathrm{MPa}$ dayanımlı betonun basınç ve çekme hasar davranışı SEM'de oluşturularak Şekil 2'de örnek olarak sunulmuştur.
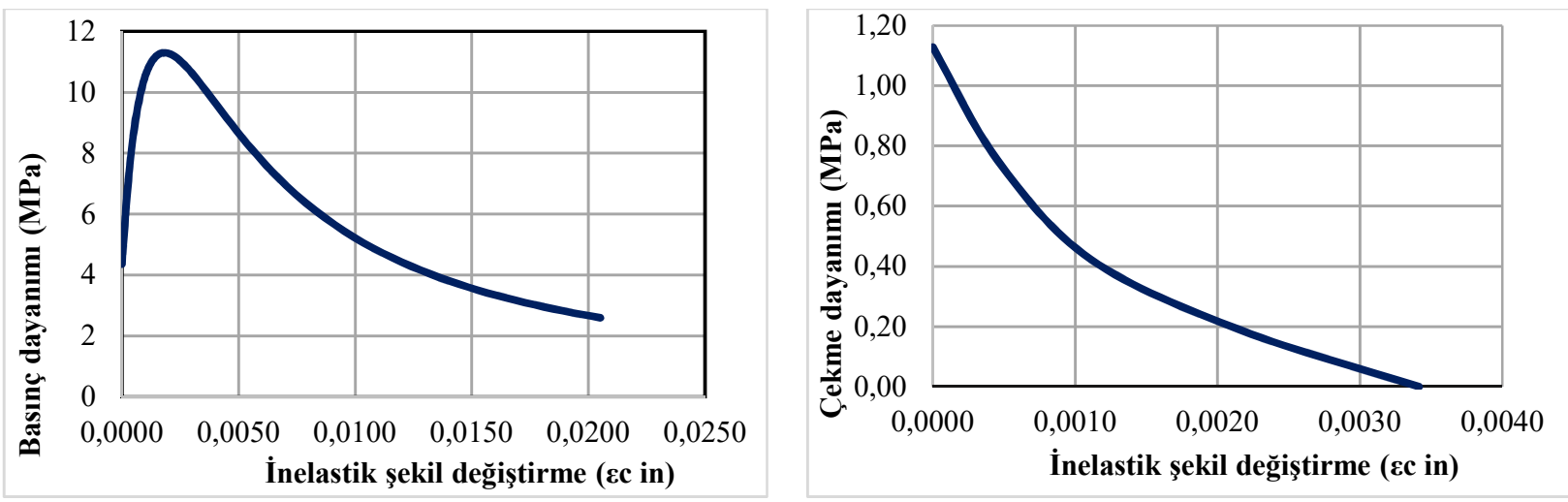

a) Basınç hasar davranışı
b) Çekme hasar davranışı

Şekil 3. $11 \mathrm{MPa}$ Basınç daynımına sahip betonun beton hasar davranışı

\subsubsection{CFRP model parametreleri}

Deney çalışmalarda kullanılmış CFRP kompozitlerin özellikleri lineer elastik olarak kabul edilmiş ve sonlu elemanlar paket programına tanımlanan parametreler Tablo 3 'te sunulmuştur.

Tablo 3. SEM modeli CFRP özellikleri:

\begin{tabular}{ll}
\hline \hline Birinci Elastisite Modülü (E1) (MPa) & 230000 \\
İkinci Elastisite Modülü (E2) (MPa) & 4500 \\
Boyuna çekme mukavemeti (MPa) & 3900 \\
Kalınlık (mm) & 0.17 \\
Dönme açısı (derece) & 0 \\
\hline \hline
\end{tabular}

\section{Deneysel ve SEM Çalışma Sonuçları}

Betonda ve CFRP kompozit üzerinde oluşan gerilme dağılımlarını gösterilmek üzere 1 kat CFRP ile güçlendirilmiş S2 betonunun sonuçları örnek olarak verilmiştir. S2 betonunun analiz sonuçları incelendiğinde maksimum gerilmelerin beton çekirdeği içerisinde ve numunenin orta bölgesinde (Şekil 4a), S2-CFRP1 betonunda FRP üzerinde oluşan maksimum gerilmeler FRP kompozitin orta bölgesine yayıldı̆̆ı görülmektedir.

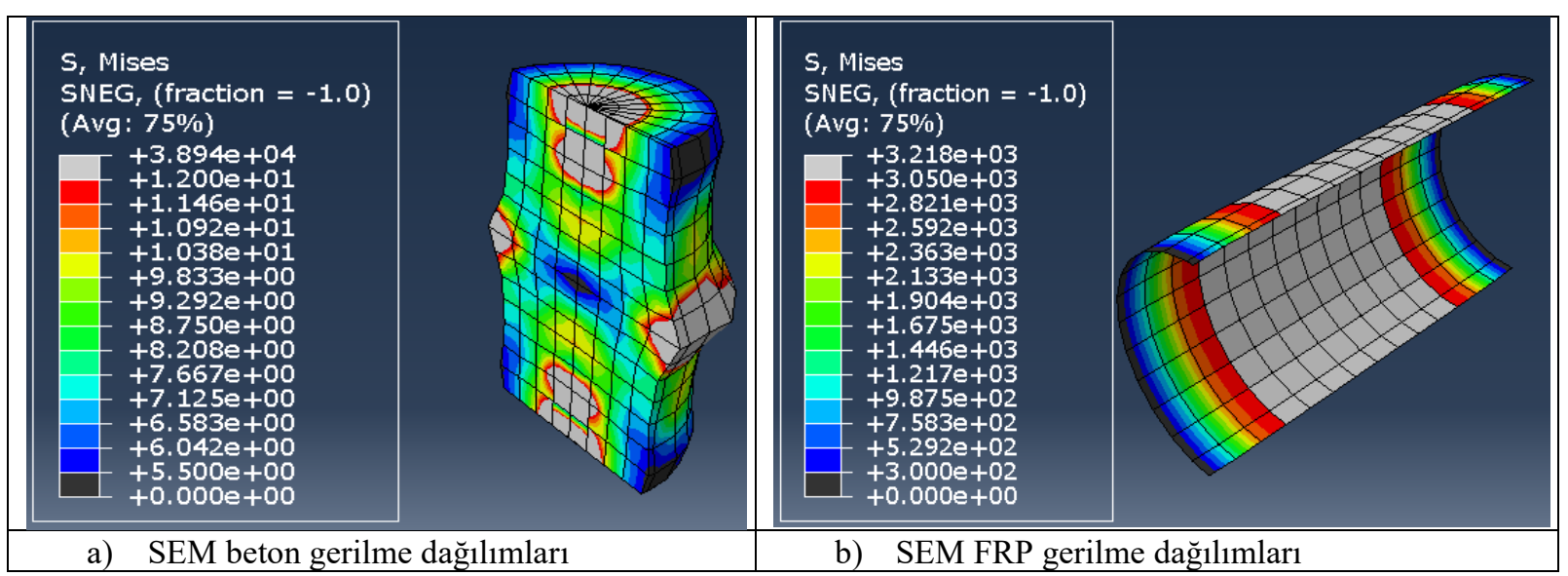

Şekil 4. SEM Beton ve FRP gerilme dağılımları

\subsection{Beton davranıs modeli analizi}

S2 betonları üzerinde model parametreleri girilerek betonların davranışı modellenmiştir. S2 betonları için mesh-wedge ve mesh-hex çözüm ağ1 türünün, $21 \mathrm{~mm}$ ağ boyutunun deneye en yakın sonucu verdiği ve çözüm ağları büyüdükçe kırılma dayanımının azaldığı gözlenmiştir. 4045 derece aralığındaki Dilasyon açısı ile model doğrulanmıştır(Şeki15). 


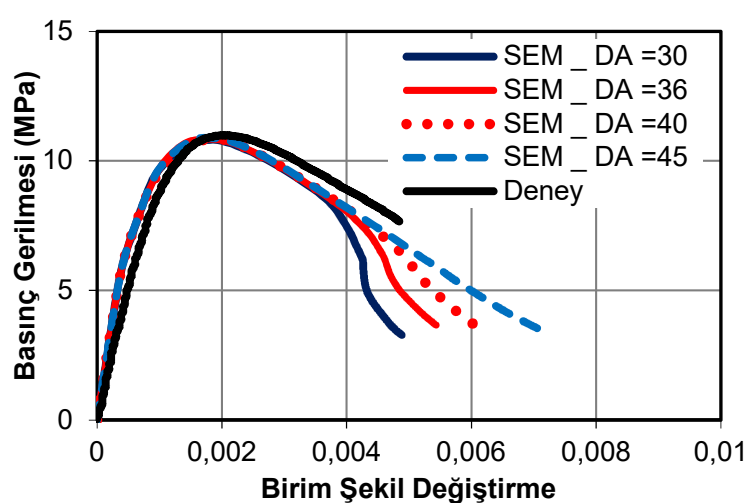

a) Ağ türü ve boyutu: Wedge, 15

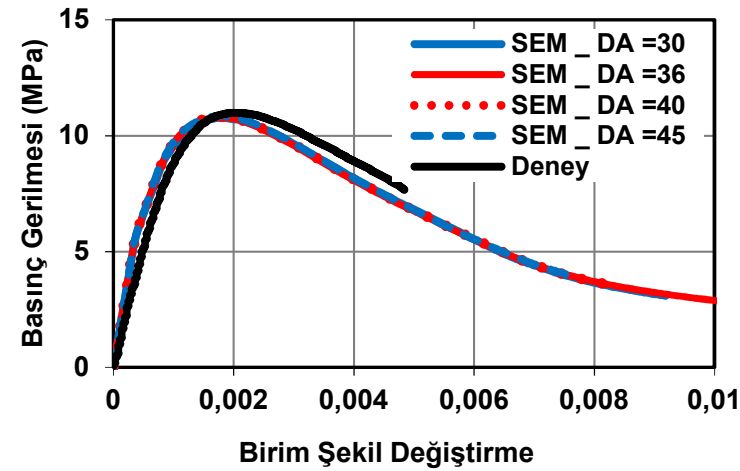

c) Ağ türü ve boyutu: Wedge, 21

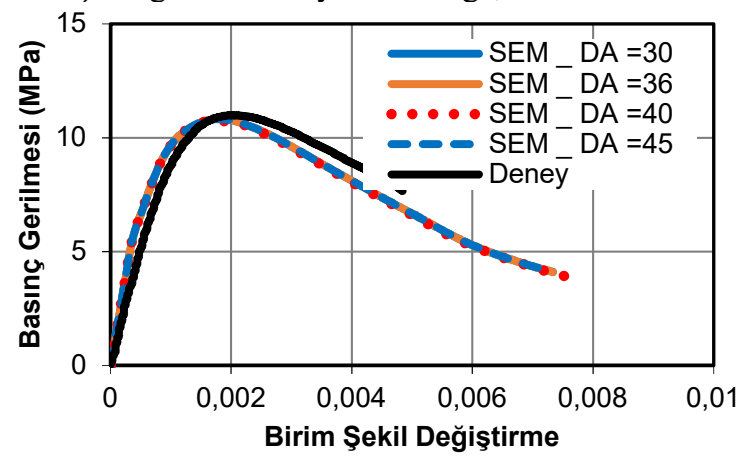

e) Ağ türü ve boyutu: Wedge, 25

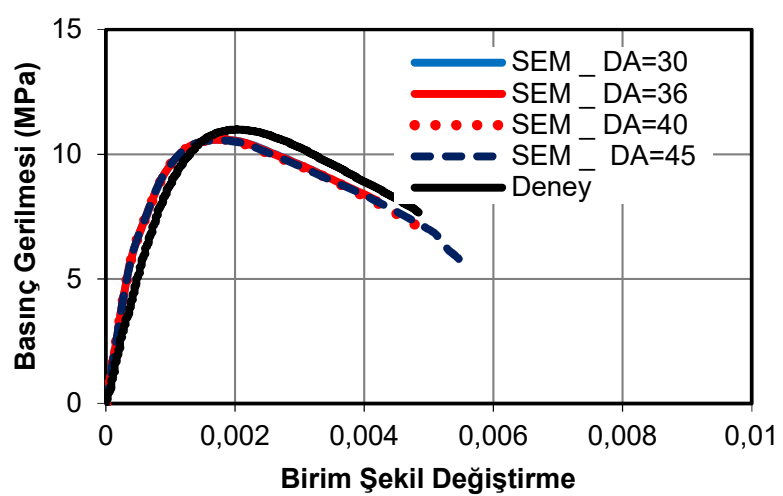

b) Ağ türü ve boyutu: Hex, 15

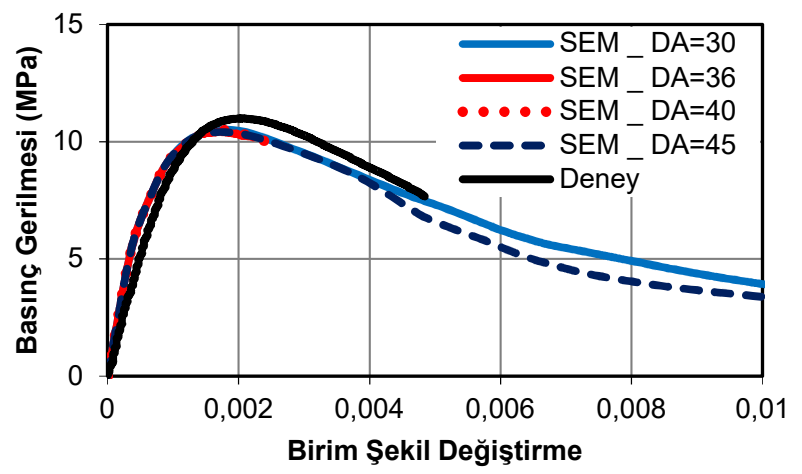

d) A ğ türü ve boyutu: Hex, 21

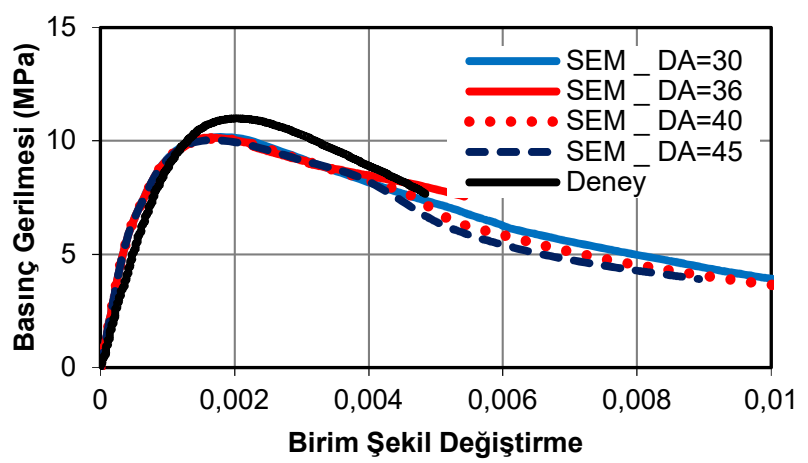

f) Ağ türü ve boyutu: Hex, 25

Şekil 5. S2 betonlarının SEM analiz sonuçları

CFRP kompozitler ile güçlendirilmiş betonlarda, hex ağ türü, $21 \mathrm{~mm}$ çözüm ağ boyutu, ve 42 dilasyon açısı deneysel çalışamaya daha uygun sonuç vermiştir. S2 serisi betonlardan elde edilen parametreler S1 serisi betonlar üzerinde de doğru sonuçlar verdiğinden yeniden parametre çalışmasına gerek duyulmamıştır.

Güçlendirilen S1 ve S2 betonların deneysel ve SEM analiz davranışları doğrulanmıştır. S1-CFRP1 betonların basınç dayanımı deney sonucuna göre 30,6 MPa SEM analizi ise 31,2 MPa, şekil değiştirme kapasitesi deney sonucuna göre 0,026 SEM analizi ise 0,024 olarak, S2-CFRP1 
betonların basınç dayanımı deney sonucuna göre 35,6 MPa abaqus analizi ise 36,1 MPa, şekil değiştirme kapasitesi deney sonucu ve SEM analizi 0,022 olarak bulunmuştur(Şekil 6).

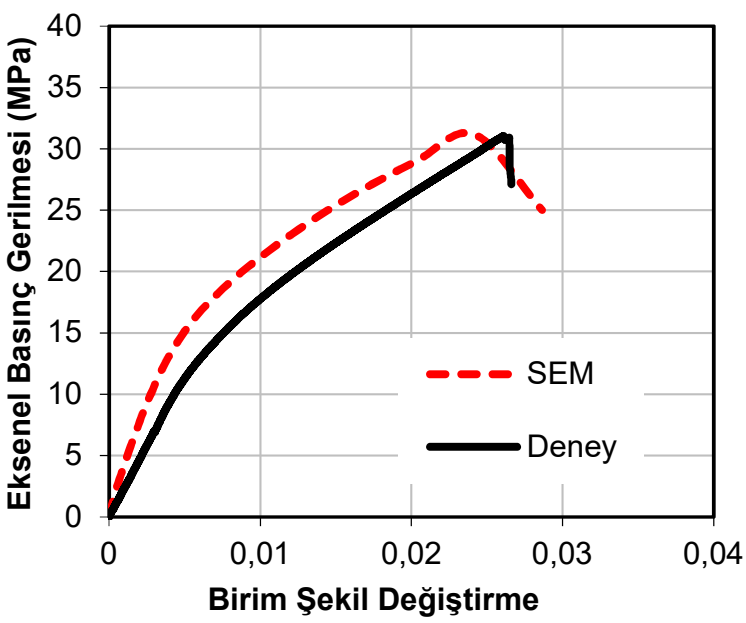

a) S1-CFRP1 deney ve SEM Sonuçları

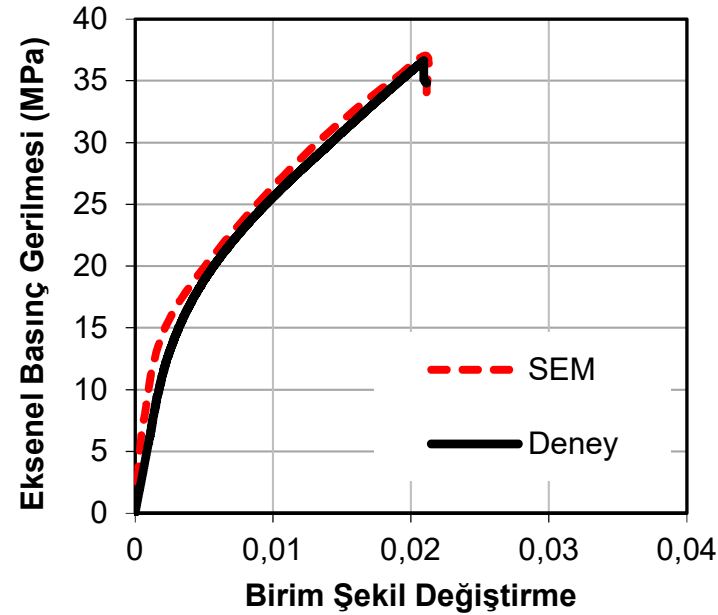

b) S2-CFRP1 deney ve SEM Sonuçları

Şekil 6. CFRP ile güçlendirilmiş betonlarının deney ve SEM analiz sonuçları

\section{Sonuçlar ve Öneriler}

Bu çalışmada, dayanımı 6-12 MPa arasında değişen iki farklı beton dayanımına sahip betonların CFRP ile güçlendirilmesi ve sonlu elemanlar ile analizleri yapılmıştır. Deneysel çalışmadan elde edilen beton davranışları sonlu elemanlar ile modellenmiş ve doğrulanmıştır. CFRP kompozitler ile güçlendirilmiş betonların deney sonuçları ve sonlu elemanlar analiz sonuçları karşılaştırılarak uygun parametreler tespit edilmiştir. Elde edilen parametreler ile S1 ve S2 seri betonlar için deney ve SEM arasındaki maksimum dayanımdaki fark \%1 olarak hesaplanmıştır. Ayrıca yenilme zarfları her iki beton dayanımı için paralellik göstermektedir. Elde edilen sonuçlara göre deneysel çalışma yapılmadan SEM analizleri ile deneysel veri üretilebilir.

\section{KAYNAKLAR}

[1] M. Saatcioglu et al., "The August 17, 1999, Kocaeli (Turkey) earthquake - damage to structures," Can. J. Civ. Eng., vol. 28, no. 4, pp. 715-737, 2001.

[2] H. Sezen, A. S. Whittaker, K. J. Elwood, and K. M. Mosalam, "Kocaeli, Turkey earthquake, and seismic design and construction practise in Turkey," Eng. Struct., vol. 25, pp. 103-114, 2003.

[3] H. Sezen, A. S. Whittaker, K. J. Elwood, and K. M. Mosalam, "Performance of reinforced concrete buildings during the August 17, 1999 Kocaeli, Turkey earthquake, and seismic design and construction practise in Turkey," Eng. Struct., vol. 25, no. 1, pp. 103-114, 2003.

[4] H. Kaplan, S. Yilmaz, H. Binici, E. Yazar, and N. Çetinkaya, "May 1, 2003 Turkey—Bingöl earthquake: damage in reinforced concrete structures," Eng. Fail. Anal., vol. 11, no. 3, pp. 279-291, 2004.

[5] A. Dogangun, "Performance of reinforced concrete buildings during $\backslash$ rthe May 1, 2003 
Bingo“ 1 Earthquake in Turkey," Eng. Struct., vol. 26, pp. 841-856, 2004.

[6] A. Doğangün, "Performance of reinforced concrete buildings during the May 1, 2003 Bingöl Earthquake in Turkey," Eng. Struct., vol. 26, no. 6, pp. 841-856, 2004.

[7] A. Bayraktar et al., "Structural Performance Evaluation of 90 RC Buildings Collapsed during the 2011 Van, Turkey, Earthquakes," J. Perform. Constr. Facil., vol. 29, no. 6, p. 4014177, 2013.

[8] M. Tapan, M. Comert, C. Demir, Y. Sayan, K. Orakcal, and A. Ilki, "Failures of structures during the October 23, 2011 Tabanli (Van) and November 9, 2011 Edremit (Van) earthquakes in Turkey," Eng. Fail. Anal., vol. 34, pp. 606-628, 2013.

[9] A. Bayraktar, A. C. Altunişik, and M. Pehlivan, "Performance and damages of reinforced concrete buildings during the October 23 and November 9, 2011 Van, Turkey, earthquakes," Soil Dyn. Earthq. Eng., vol. 53, pp. 49-72, 2013.

[10] E. Çelebi et al., "October 23, 2011 Turkey/Van-Ercis earthquake: Structural damages in the residential buildings," Nat. Hazards, vol. 65, no. 3, pp. 2287-2310, 2013.

[11] E. Damci, R. Temur, G. Bekdaş, and B. Sayin, "Damages and causes on the structures during the October 23, 2011 Van earthquake in Turkey," Case Stud. Constr. Mater., vol. 3, pp. 112-131, 2015.

[12] R. Eid and P. Paultre, "Compressive behavior of FRP-confined reinforced concrete columns,” Eng. Struct., vol. 132, pp. 518-530, 2017.

[13] A. Mirmiran and M. Shahawy, "Behavior of Concrete Columns Confined by Fiber Composites," J. Struct. Eng., vol. 123, no. 5, pp. 583-590, 1997.

[14] M. Shin and B. Andrawes, "Experimental investigation of actively confined concrete using shape memory alloys,” Eng. Struct., vol. 32, no. 3, pp. 656-664, 2010.

[15] Y.-Z. Zhong, Q. Yu, and Z. Tao, "Compressive behaviour of CFRP-confined rectangular concrete columns," Mag. Concr. Res., vol. 60, no. 10, pp. 735-745, 2008.

[16] M. Seffo and M. Hamcho, "Strength of concrete cylinder confined by composite materials (CFRP)," in Energy Procedia, 2012, vol. 19, pp. 276-285.

[17] T. Ozbakkaloglu and E. Akin, "Behavior of FRP-Confined Normal- and High-Strength Concrete under Cyclic Axial Compression," J. Compos. Constr., vol. 16, no. 4, pp. 451463, 2012.

[18] A. Ilki, O. Peker, E. Karamuk, C. Demir, and N. Kumbasar, "FRP Retrofit of Low and Medium Strength Circular and Rectangular Reinforced Concrete Columns," J. Mater. Civ. Eng., vol. 20, no. 2, pp. 169-188, 2008.

[19] J. Li and M. N. S. Hadi, "Behaviour of externally confined high-strength concrete columns under eccentric loading," Compos. Struct., vol. 62, no. 2, pp. 145-153, 2003.

[20] A. Ilki, N. Kumbasar, and V. Koç, "Low and medium strength concrete members confined by fiber reinforced polymer jackets," ARI Bull. Istanbul Tech. Univ., vol. 53, no. 1, 2003.

[21] H. Toutanji and Y. Deng, "Strength and durability performance of concrete axially loaded members confined with AFRP composite sheets," Compos. Part BEngineering, vol. 33, no. 4, pp. 255-261, 2002.

[22] H. Saadatmanesh, M. R. Ehsani, and M. W. Li, "Strength and ductility of concrete columns externally reinforced with fiber composite straps," ACI Struct. J., vol. 91, no. 4, pp. 434447, 1994.

[23] A. Ilki, N. Kumbasar, and V. Koc, "Low strength concrete members externally confined with FRP sheets," Struct. Eng. Mech., vol. 18, no. 2, pp. 167-194, 2004.

[24] H. A. Toutanji, "Stress-strain characteristics of concrete columns externally confined with 
advanced fiber composite sheets," ACI Mater. J., vol. 96, no. 3, pp. 397-404, 1999.

[25] L. Lam, J. G. Teng, C. H. Cheung, and Y. Xiao, "FRP-confined concrete under axial cyclic compression," Cem. Concr. Compos., vol. 28, no. 10, pp. 949-958, 2006.

[26] M. F. Green, L. A. Bisby, A. Z. Fam, and V. K. R. Kodur, "FRP confined concrete columns: Behaviour under extreme conditions," Cem. Concr. Compos., vol. 28, no. 10, pp. 928-937, 2006.

[27] J. G. Teng and L. Lam, "Behavior and modeling of fiber reinforced polymer-confined concrete," J. Struct. Eng., vol. 130, no. 11, pp. 1713-1723, 2004.

[28] J. G. Teng, Y. M. Hu, and T. Yu, "Stress-strain model for concrete in FRP-confined steel tubular columns," Eng. Struct., vol. 49, pp. 156-167, 2013.

[29] R. Kumutha, "Behaviour of reinforced concrete rectangular columns strengthened using GFRP," vol. 29, pp. 609-615, 2007.

[30] H.-J. Lin and C.-I. Liao, "Compressive strength of reinforced concrete column confined by composite material," Compos. Struct., vol. 65, no. 2, pp. 239-250, 2004.

[31] L. Lam and J. G. Teng, "Stress-strain model for FRP-confined concrete under cyclic axial compression," Eng. Struct., vol. 31, no. 2, pp. 308-321, 2009.

[32] P. Yin, L. Huang, L. Yan, and D. Zhu, "Compressive behavior of concrete confined by CFRP and transverse spiral reinforcement. Part A: experimental study," Mater. Struct., vol. 49, no. 3, pp. 1001-1011, 2016.

[33] Dassault Systèmes Simulia, A. . Fallis, and D. Techniques, ABAQUS documentation, vol. 53, no. 9. 2013, pp. 1689-1699.

[34] M. H. Al-sherrawi, "Finite Element Modeling of a Reinforced Concrete Column Strengthened with Steel Jacket Finite Element Modeling of a Reinforced Concrete Column Strengthened with Steel Jacket," no. June, 2018.

[35] F. O. F. Civil, "Identification of parameters of concrete damage plasticity constitutive model," no. 6, 2005.

[36] J. Chróścielewski, M. Miśkiewicz, Pyrzowski, and B. Sobczyk, "Damage Analysis of Tensioning Cable Anchorage Zone of a Bridge Superstructure, Using CDP Abaqus Material Model," Arch. Civ. Eng., vol. 63, no. 3, pp. 3-18, 2017.

[37] A. Sarıbıyı, "Beton Dayanimi Düşük Betonarme Yapi ElemanlariniLifliKompozitlerGüçlendirilmesi Ve Karşilaştirilmasi,” Sak. Üniversitesi Fen Bilim. Enstitüsü, 2013. 